\author{
A Mbaye ${ }^{1}$, AA Ngaïde ${ }^{1}$, ND Gaye ${ }^{1}$, M \\ $\mathrm{Gazal}^{2}, \mathrm{M} \mathrm{Ka}^{1}, \mathrm{M} \mathrm{Faye}^{4}, \mathrm{~K}$ Babaka${ }^{1}, \mathrm{G}$ \\ Lo $^{1}$, E Kluvi ${ }^{1}$, JS Mingou ${ }^{2}$, M Dioum ${ }^{6}$, \\ K Niang 5 , F Aw ${ }^{2}$, A Dodo' ${ }^{2}$, SA Sarr ${ }^{2}$, \\ M Bodian², MB Ndiaye ${ }^{2}$, Ad Kane ${ }^{2}$, M \\ Ndour-Mbaye ${ }^{3}$, I Thiaw ${ }^{7}$, A Kane $^{1}$ \\ ${ }^{1}$ Cardiology department of Grand-Yoff general \\ hospital, Dakar, Senegal \\ ${ }^{2}$ Cardiology department of Aristide Le-Dantec \\ hospital, Dakar, Senegal \\ ${ }^{3}$ Internal Medicine department of Abass-Ndao \\ hospital, Dakar, Senegal \\ ${ }^{4}$ Hephrology department of Aristide Le Dantec \\ hospital, Dakar, Senegal \\ ${ }^{5}$ Public health institute of Cheikh Anta Diop \\ university, Dakar, Senegal \\ ${ }^{6}$ Cardiology department of Fann hospital, Dakar- \\ Fann, Senegal \\ ${ }^{7}$ Primare health center of Gueoul, Senegal \\ Dates: Received: 10 May, 2016; Accepted: 27 July, \\ 2016; Published: 04 July, 2016 \\ *Corresponding author: Dr. Alassane Mbaye, \\ MD, Cardiology Department of Grand-Yoff General \\ Hospital, Postal Box: 3270, Dakar, Sénégal Tel: \\ 00221 775660649; E-mail: ambaye8@hotmail.com \\ www.peertechz.com \\ Keywords: Hypertension; Cardiovascular risk factors; \\ Complications; Africa
}

\section{Research Article \\ Hypertension, Cardiovascular Risk Factors and Complications in Large Population Based Study in Senegal}

\begin{abstract}
Objectives: We aim to determine the prevalence of hypertension, cardiovascular risk factors and complications among the population living in the semi-rural area of Gueoul in Senegal.

Matariels and method: This is a cross-sectional, descriptive study. In 2012, we conducted an exhaustive survey according to the STEPSwise approach of the world health organization among Senegalese aged of 35 years and over who resided for at least 6 months in semi-rural area. Pregnant women were excluded. Cardiovascular risk factors and complications were collected and data analyzed using SPSS 18.0 software. The significance level was agreed for a value of $p<0.05$.

Results: We examined 1411 subjects (1052 women) with a mean age of $48.5 \pm 12.68$ years. The prevalence of hypertension was $46,4 \%$. The other cardiovascular risk factors were dyslipidemia $(61,1 \%)$, sedentarity $(56.2 \%)$, abdominal obesity according to the International Diabetes Federation $(53.9 \%)$, global obesity (13\%), diabetes (7.2\%) and smoking (2.5\%). Hypertension was known in $19 \%$ of case and detected in $27.4 \%$. It was more frequent in subjects over 65 years $(p=0.001)$, in those with diabetes $(p=0.001)$, abdominal $(p=0.001)$ or global $(p=0.0001)$ obesity. Some complications occurred as soon as peripheral arterial disease $(28.6 \%)$, coronary artery disease $(18.6 \% \%)$, kidney disease $(37 \%)$ and carotid atheroma (8.6\%). Hypertensive subjects presented more frequently kidney disease $(p=0.0001)$ and carotid atheroma $(p=0.0001)$ as far as, left ventricular hypertrophy was
\end{abstract} noted in $16.7 \%$ of them.

Conclusion: Hypertension and other cardiovascular risk factors are frequent and often associated with complications in semi-rural area of Senegal. Adapted strategies are necessary to prevent serious cardiovascular diseases.

\section{Introduction}

Atheromatous disease is rapidly expanding in Africa [1], though often undervalued because of the lack of screening. It is related to cardiovascular risk factors, more and more described in Africa [1]. Contrary to general opinion, epidemiological studies show that nearly $80 \%$ of deaths from non-communicable diseases (NCD) occur in low- and middle-income countries [2]. A survey conducted in Senegal in urban areas in 2010 [3], revealed a high prevalence of hypertension and other cardiovascular risk factors. Our objectives were to assess the prevalence of hypertension, risk factors and cardiovascular complications in a Senegalese general population living in semi-rural areas in the municipality of Guéoul, Senegal.

\section{Materiels and Method}

\section{Framework, period and type}

Our study was conducted in the municipality of Gueoul, in the northwest of Senegal. It is located on the National Road Number 2, about 169 kilometers from Dakar, the capital of Senegal. The village was turned into a town in 2008 and has 10,918 inhabitants according to a 2002 report. The population is mostly young and generally made up of women. The subjects aged 35 years at least were approximately 1,500 people [4].
We carried out, 3 November to 3 December 2012, an observational, transversal and comprehensive study. It was based on the STEP wise approach of the World Health Organization (WHO) as a standardized, replicable and flexible tool [5].

\section{Selecting the population}

This is a comprehensive survey, inclusively targeting all subjects aged 35 years at least and who had been residing in semi-rural area in the municipality of Guéoul for at least 6 months. No sampling was made and only pregnant women were not included. For recruitment, the subjects were informed in advance and invited, according to the district they were living, to the place of investigation. Absentees were called the following days.

\section{Performance of the study}

Authorization of the administrative authorities was obtained before starting the investigation, and first a sensitizing campaign had been conducted through community health workers one month before the beginning of the survey, and throughout its development.

A multidisciplinary team including cardiologists, diabetologists, nephrologists, epidemiologists and the chief medical officer of Gueoul drafted the questionnaire based on the WHO's STEPS wise approach. Investigators were trained beforehand and the collected data were saved on computers by double entry. Informed consent in French was 
signed by the participants. Subjects who could not read were assisted by an interpreter for translation into local languages.

The blood pressure (BP) was measured using OMRON M6 electronic sphygmomanometer. Each subject was systematically submitted to 2 consecutive BP measurements, performed by the same technician after 10 minutes' rest, sitting and in both arms. The highest figures were retained.

Weight was measured in kilograms $(\mathrm{kg})$, height and waist circumference in centimeters. A blood sample was collected from all subjects concerned after a 12-hour fasting period. Biological samples were analyzed using a BTS 350 spectrophotometer. A dipstick test was conducted on a urine sample, renal ultrasound was also used. All subjects underwent an electrocardiogram (ECG) with double, Adan and Fukuda 3-channel electrocardiographs and echocardiography by means of a portable Sonosite, fitted with $2.5 \mathrm{MHz}$ and $5 \mathrm{MHz}$ probes with pulsed, continuous, color and tissue Doppler. An ultrasound of the neck vessels was performed using the same apparatus. The ankle brachial index (ABI) was measured with a Doppler pocket type DIADOP.

\section{Data studied}

The following parameters were studied:

- Socio-demographic data: age, sex, academic level, socioprofessional category.

- The history of hypertension, diabetes, dyslipidemia, heart disease, stroke or kidney disease;

- The history among first degree relatives of coronary heart disease or sudden death;

- The lifestyle in terms of tobacco addiction, excessive alcohol consumption, physical activity and diet;

- The anthropometric data on blood pressure, heart rate, weight, height, waist circumference and body mass index (BMI);

- Fasting blood glucose, cholesterol, creatinine, glomerular filtration rate as per MDRD formula, proteinuria, urine leukocytes detected with dipsticks.

- The index of systolic pressure, carotid intima-media thickness, index of Sokolow-Lyon and signs of coronary disease using electrocardiogram.

- Kidney morphology (size, renal cortical differentiation, cysts).

\section{Definition of operational variables}

Sedentarity was defined as the absence of daily physical activity or physical activity timeless than 120 minutes per week. Smoking was for a current consumption of tobacco or stopped for less than 3 years [5]. Was considered hypertensive subject, anyone with a history of hypertension or systolic blood pressure $\geq 140 \mathrm{~mm} \mathrm{Hg}$ and/or diastolic blood pressure $\geq 90 \mathrm{mmHg}$ [6]. Diabetes was accounted for in every subject known as diabetic or whose fasting glucose, measured twice was $\geq 1.26 \mathrm{~g} / \mathrm{l}$ or anyone with a fasting glucose $\geq 1.26 \mathrm{~g} / \mathrm{l}$ but showing signs suggestive of diabetes. Dyslipidemia was defined according to the criteria of the National Cholesterol Education Program Adult Treatment Panel III (NCEP ATPIII) [7]. Abdominal obesity was defined according to the International Diabetes Federation (IDF) with waist size $\geq 94 \mathrm{~cm}$ in men and $\geq 80 \mathrm{~cm}$ in women [8]. Body mass index (BMI) defined global obesity to a value $\geq 30 \mathrm{~kg} / \mathrm{m}^{2}$. Kidney disease was defined as creatinine clearance $<60 \mathrm{ml} / \mathrm{min}$, renal morphological abnormality, proteinuria or leucocyturia by means of test strips [9]. The carotid plaque was defined by the presence of a thickening of the wall exceeding $50 \%$ immediately upstream or downstream of the wall or as a localized zone with an intima-media thickness $>1.5 \mathrm{~mm}$ protruding into the arterial lumen [10], and peripheral arterial disease for anckle bchial index $(\mathrm{ABI})<0.9$ [11]. Left ventricular hypertrophy (LVH) was sought in hypertensive subjects, defined using ECG according to a Sokolow-Lyon index $\geq 35 \mathrm{~mm}$ $[12,13]$. Coronary heart disease was retained according to Minnoseta code for probable (wide or average Q wave) or potential coronary artery disease (small q wave, with ST-segment elevation, negative $\mathrm{T}$ wave, and complete left bundle branch block) $[14,15]$.

\section{Statistical analysis}

The data were entered with Epi Info version 3.5.1 and analyzed by means of SPSS 18.0 software. The Chi-square test 2 was used for comparing proportions. The significance threshold was set for a p-value lower than $5 \%$.

\section{Results}

The survey involved 1411 subjects for a target population of 1500 people (94\%). There were more women with 1052 subjects (74.6\%) and the mean age was $48.5 \pm 12.7$ years. The respective frequency of cardiovascular risk factors and their distribution by gender are shown in Table 1.

The prevalence of Hypertension was $46.4 \%$ (655 subjects). It was grade I in $42.6 \%$ of cases, grade II and III respectively in $28.6 \%$ and $28.8 \%$. It prevailed, without significant statistical difference in men $(\mathrm{p}=0.095)$. Moreover, prevalence increased with age regardless of gender (Figure 1). It was more frequent in unschooled subjects (49.2\%) than among schooled subjects (41.9\%) with a statistically significant difference $(\mathrm{p}=0.007)$. It was known in 266 cases $(19 \%)$ and detected in 389 (27.4\%). Among the known hypertensive subjects, average disease duration was 4.6 years, ranging from 0.8 to 30 years. $88.5 \%$

Table 1: Prevalences of cardiovascular risk factors and comparaison by gender $(n=1411)$.

\begin{tabular}{|l|l|l|l|l|}
\hline Cardiovascular risk factors & Total & Women & Men & P-value \\
\hline Dyslipidémia & $61,1 \%$ & $65,4 \%$ & $48,5 \%$ & 0,0001 \\
\hline Sedentarity & $56,2 \%$ & $55,2 \%$ & $58,5 \%$ & 0,28 \\
\hline Abdominal obesity (IDF) & $53,9 \%$ & $65,2 \%$ & $20,6 \%$ & 0,0001 \\
\hline Hypertension & $46,4 \%$ & $45,1 \%$ & $50,1 \%$ & 0,095 \\
\hline Obesity (BMI $\geq \mathbf{3 0} \mathbf{~ k g / \mathbf { m } ^ { 2 } )}$ & $13 \%$ & $15,9 \%$ & $4,5 \%$ & 0,0001 \\
\hline Metabolic syndrom (IDF) & $19,8 \%$ & $24,4 \%$ & $6,1 \%$ & 0,0001 \\
\hline Diabetes & $7,2 \%$ & $6,6 \%$ & $9,2 \%$ & 0,096 \\
\hline Smoking & $2,5 \%$ & $9,2 \%$ & $0,2 \%$ & 0,001 \\
\hline IDF = international diabetes federation, BMI = body mass index & \\
\hline
\end{tabular}


of them were known hypertensive for more than 1 year, and medical treatment was prescribed in $77 \%$ of cases (205/266), combined with herbal medicine in $24.7 \%$ and lifestyle changes in $29.6 \%$. The control rate of blood pressure was $12.7 \%$ (26/205). Table 2 shows the prevalence of cardiovascular risk factors in hypertensive compared to non-hypertensive subjects. The analysis of the table shows that the hypertension was more frequently associated with diabetes $(\mathrm{p}=$ $0.001)$, with overall $(p=0.0001)$ or abdominal $(p=0.001)$ obesity and with metabolic syndrome $(\mathrm{p}=0,0001)$.

The prevalence of dyslipidemia was $61,1 \%$. It was known in $1.5 \%$ of cases, and detected in $59.5 \%$. It was more common in women ( $\mathrm{p}$ $=0.0001$ ). Sedentarily was noted in $56.2 \%$ of cases, more common in men $(58.5 \%)$ than women $(55.2 \%)$ with no statistically significant difference $(p=0.28)$. It was more common in subjects aged $75-84$ years $(\mathrm{p}=0.0001)$. It was more frequent in non-schooled subjects (58\%) than in schooled (53\%) without significant difference $(\mathrm{p}=$ 0.07 ). The prevalence of abdominal obesity was $53.9 \%$. It involved more women $(65 \%)$ than men $(20.6 \%)(p<0.0001)$. It prevailed also in subjects aged 45 to $54(\mathrm{p}=0.01)$, out-of-school subjects $(\mathrm{p}=0.01)$ and housewives $(\mathrm{p}=0.0001)$. Obesity as per BMI was more frequent ( $\mathrm{p}<0.0001)$ in women $(16 \%)$ than in men $(4.5 \%)$. Prevalence also increased with age, predominant in subjects aged 55 to $64(\mathrm{p}=0.024)$.

Diabetes was found at a rate of $7.2 \%$ about $5.4 \%$ of known diabetics and $1.8 \%$ of new cases. The average disease length was 7.25 years. It was more common among men (9.2\%) than women (6.6\%) without

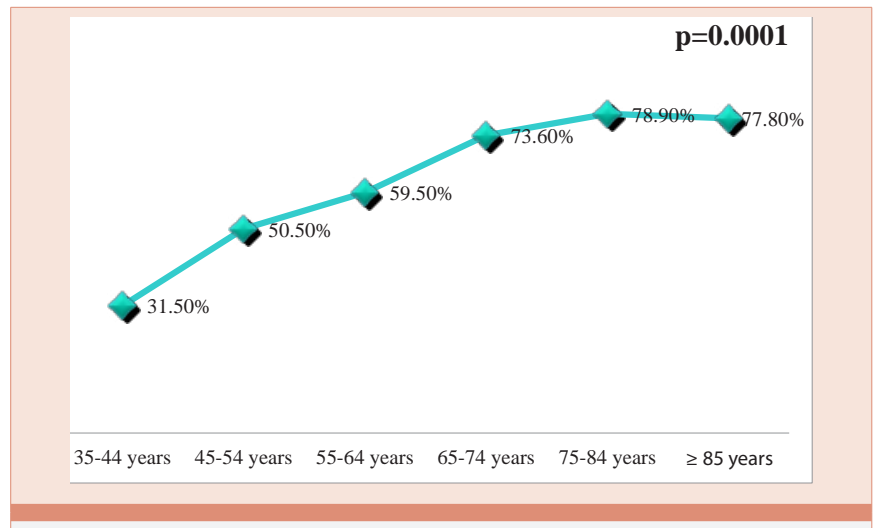

Figure 1: prevalence of hypertension according to age $(n=1411)$.

Table 2: prevalence of cardiovascular risk factors in hypertensive compared to non-hypertensive subjects $(n=1411)$.

\begin{tabular}{|l|l|l|l|}
\hline Cardiovascular risk factors & Hypertensive & $\begin{array}{l}\text { non } \\
\text { hypertensive }\end{array}$ & P-value \\
\hline Diabetes & $62,7 \%$ & $45,1 \%$ & 0,001 \\
\hline Dyslipidémia & $62,2 \%$ & $60,1 \%$ & 0,414 \\
\hline Abdominal obesity (IDF) & $67 \%$ & $41,3 \%$ & 0,001 \\
\hline Obesity (BMI $\geq 30 \mathbf{~ k g / m ^ { 2 } )}$ & $59 \%$ & $44,5 \%$ & 0,0001 \\
\hline Sedentarity & $62,2 \%$ & $53,8 \%$ & 0,062 \\
\hline Metabolic syndrom (IDF) & $28,6 \%$ & $12,2 \%$ & 0,0001 \\
\hline Smoking & $48,6 \%$ & $46,3 \%$ & 0,79 \\
\hline
\end{tabular}

IDF = international diabetes federation, $\mathrm{BMI}=$ body mass index statistically significant difference $(\mathrm{p}=0.096)$. In men, it predominated in the elderly between 55 and 74 years $(14.4 \%)(p=0.0001)$. Similarly, it prevailed in sedentary $(\mathrm{p}=0.0001)$ and hypertensive subjects $(\mathrm{p}=$ $0.001)$.

Smoking prevalence was $2.5 \%$, about $9.4 \%$ of men and $0.2 \%$ of women $(\mathrm{p}<0.001)$. It was more common among schooled subjects (5.2\%) than those unschooled $(1.2 \%)(\mathrm{p}=0.004)$.

The prevalence of metabolic syndrome was $19.8 \%$, more predominant among women (24.4\%) than men $(6.1 \%)(\mathrm{p}=0.0001)$. Complications evidencing target organ damage or cardiovascular disease were noted. Thus, chronic kidney disease was found in 515 cases $(36.5 \%)$. This was most often a decrease in the glomerular filtration rate $<60 \mathrm{ml} / \mathrm{min}(206$ cases $=15.6 \%)$. Renal morphological abnormalities (small kidneys or poor cortico-medullary differentiation) was noted in 98 cases (7\%) and renal cysts in 17 cases (1.2\%). Sixty-eight patients had proteinuria $>2+$ (crosses) using the urine strips. Kidney disease was more common in hypertensive $(55.5 \%$ against $44.5 \%)(\mathrm{p}=0.001)$. Asymptomatic PAD was found in 403 patients (28.6\%) and artery sclerosis with $\mathrm{ABI}>1.2$ in 183 subjects (14.5\%). The PAD was more common in subjects aged over 85 years $(\mathrm{p}=0.011)$ and in smokers $(\mathrm{p}=0.053)$. Carotid plaques were found in 96 cases $(6.8 \%)$ of which 41 turned out to be bilateral. They were associated with hypertension $(\mathrm{p}=0.0001)$, at the advanced age $(\mathrm{p}=0.001)$, diabetes $(\mathrm{p}=0.004)$ and metabolic syndrome $(\mathrm{p}=$ 0.008 ). LVH was found in $16.7 \%$ of hypertensive patients. It was more common in men $(\mathrm{p}=0.002)$, grade- 3 hypertensive subjects $(\mathrm{p}=$ $0.0001)$ and those on medical treatment $(\mathrm{p}=0.022)$. Coronary artery disease, was recorded in 263 cases (18.6\%), 81\% of them were women $(213 / 263)$ and $19 \%$ of men (50/263). According to the Minnesota code, it was usually possible in $65.4 \%$ of cases $(172 / 263)$ and probable in $34.6 \%(91 / 263)$. It was more common in the hypertensive (54\%) and subjects with dyslipidemia (58.2\%). History of stroke was found in $2.8 \%$ of cases, most often in hypertensive patients $(\mathrm{p}<0.001)$ and heart disease was noted in $1.7 \%$ of subjects.

\section{Comment}

This survey is one of the few studies on the general population in Senegal $[3,16,17]$. It helped to collect additional data on the prevalence of cardiovascular risk factors in Senegal's general population. These data will be useful in developing strategies for cardiovascular disease prevention at national level.

The high prevalence of cardiovascular risk factors at Gueoul have confirmed the results obtained in urban areas of Saint Louis, Senegal, in 2010 [3]. They are higher than those found in most African surveys conducted mostly in urban areas [18-23]. The prevalence of hypertension confirms the current growing trend of this cardiovascular risk factor in Africa [21-24]. Among the known hypertensive subjects, control of hypertension is low comparable to certain data [24]. However, it is well below the figures in developed countries. A survey conducted in Ontario showed a $66 \%$ control rate, and 56\% for another study in the United States [25]. In Africa, the STEPS surveys have reported prevalence of obesity, defined as BMI, greater than found in our study with $20.9 \%$ in Mauritania [21] and $20.1 \%$ in Gabon [23]. Female predominance could result from 
sedentary lifestyle and especially the fact that being overweight is seen as an aesthetic criterion or a sign of social comfort in women in sub-Saharan Africa. These bad habits can also cause diabetes, and prevalence is in the rise in all countries, with epidemic proportions in some areas. Diabetes prevalence estimated at $4 \%$ in Senegal in the past [26], increases and approximates the statistics collated in Europe [27]. In Africa, the STEPS surveys conducted in population, showed a prevalence of 6\% in Mauritania in 2007 [21], 4.6\% in Benin [20], and $7 \%$ in the Congo [22]. Prevalence was highest in urban areas in Senegal in 2010 with $10.4 \%$ [3]. Smoking was the cardiovascular risk factor that prevalence of which was lowest $(2.5 \%)$, lower than that found in Tunisia with $30.4 \%$ [28]. This low prevalence in smoking could be explained by religious beliefs that prohibit the use of tobacco in general and particularly in women who were the majority in our study population. These cardiovascular risk factors often associated with the origin of cardiovascular complications can be silent, screened by simple means such as electrocardiogram, measurement of creatinine, detection of proteinuria in the urine strips, the measurement of ABI or carotid intima-media thickness. Thus, we found a high prevalence of kidney disease and asymptomatic PAD. LVH and increased intima-media thickness are considered early factors for developing cardiovascular diseases.

\section{Conclusion}

Our study showed a high prevalence of hypertension and cardiovascular risk factors in Senegalese semi-rural area. Frequent associations of risk factors cause cardiovascular complications. These data should encourage the authorities to develop strategies to fight against these diseases in Senegal.

\section{References}

1. Bertrand E, Muna WFT, Diouf SM, Ekra A, Kane A, et al. (2006) Cardiovascular emergencies in Subsaharan Africa. Arch Mal Coeur 99: 1159-1165.

2. Word Health Organization (WHO) (2014) Global status report on noncommunicable diseases.

3. Pessinaba S, Mbaye A, Yabéta GAD, Harouna H, Sib AE, et al. (2013) Prevalence survey of cardiovascular risk factors in the general population in St Louis (Senegal). Ann Cardiol Angéiol 62: 253-258.

4. National Agency of Statistics and Demography (NASD) (2009) Economical and social situation of Senegal in 2009.

5. World Health Organization (2002) Chronic diseases and health promotion. STEPwise approach to surveillance. Geneva.

6. Mancia G, Fagard R, Narkiewicz K, Redo'n J, Zanchetti A, et al. (2013) 2013 ESH/ESC guidelines for the management of arterial hypertension: the Task Force for the Management of Arterial Hypertension of the European Society of Hypertension (ESH) and of the European Society of Cardiology (ESC). Eur Heart J 34: 2159-219.

7. Grundy SM, Cleeman JI, Daniels SR, Donato KA, Eckel RH, et al. (2005) Diagnosis and management of the metabolic syndrome: an American Heart Association/National Heart, Lung, and Blood Institute Scientific Statement (executive summary). Circulation 112: 2735-2752.

8. Alberti KGMM, Zimmet PZ, Shaw J, IDF Epidemiology Task Force Consensus Group (2005) The metabolic syndrome: a new worldwide definition. Lancet 366: 1059-1062.

9. Rutkowski M, Mann W, Derose S, selevan D, Pascual N, Diesto J, et al. (2009) Implementing KDOQI CKD definition and staging guidelines in Southern California Kaiser Permanente. Am J Kidney Dis 53: 86-99.
10. Stein JH, Korcarz CE, Hurst RT, Lonn E, Kendall CB, et al. (2008) Use of carotid ultrasound to identify subclinical vascular disease and evaluate cardiovascular disease risk: A consensus statement from the American Society of Echocardiography Carotid Intima-Media Thickness Task Force. Endorsed by the Society for Vascular Medicine. J Am Soc Echocardiogr 21: 93-111.

11. European Stroke Organisation1, Tendera M, Aboyans V, Bartelink ML, Baumgartner I, et al. (2011) ESC Guidelines on the diagnosis and treatment of peripheral artery disease $\mathrm{s}$ : Document covering atherosclerotic disease of extracranial carotid and vertebral, mesenteric, renal, upper and lower extremity arteries: the Task Force on the Diagnosis and Treatment of Peripheral Artery Diseases of the European Society of Cardiology (ESC). Eur Heart J 32: 2851-2906

12. Gosse P, Cremer A (2011) Left ventricular hypertrophy in hypertensive: review and opinion. Arch Mal Cœur Vaiss-Pratique 202: 16-20.

13. Martina B (2007) Arterial hypertension and left ventricular hypertrophy. Primary Care 7: 40-41.

14. Chen $\mathrm{CH}$, Chuang JH, Kuo HS, Chang MS, Wang SP, et al. (1996) Prevalence of coronary heart disease in Kin-Chen, Kinmen. Int J Cardiol 55: 87-95.

15. D De Bacquer, G De Backer, M Kornitzer (2000) Prevalences of ECG findings in large population-based samples of men and women. Heart 4: 625-633.

16. Kane A, Ly M, Ba SA, Diop AK, Diao M, et al. (1997) Clinical study of vascular risk factors in the adult in the Thiadiaye rural environment. Dakar Med 42: 77 82.

17. Mbaye A, Ndiaye MB, Kane Ad, F. Ndoume, S Diop, et al. (2011) Screening of cardiovascular risk factors among workers of a private tele-communication company in Senegal. Arch Mal Prof Environ 72: 96-99.

18. Ivory Coast ministry of health and public health. Survey of risk factors of noncommunicable diseases.

19. (2006) Republic of Niger, ministry of public health, general dierction of public health, direction management's disease and endemy control. Survey of risk factors of non-communicable diseases in Niger.

20. (2007) Republic of Benin. National program of management's non communicable diseases. Final Report of the STEPS survey in Cotonou, Benin 2007.

21. Islamic republic of Mauritania/ministry of health (2006) Survey of noncommunicable diseases according to WHO STEP wise approach: study of arterial hypertension, diabetes and other risk factors. Nouakchott MAURITANIA January-June 2006

22. Kimbally KG, Bolanda JD, Charlotte GO, Ngampo S, Nzoutani L, et al. (2004) Survey of hypertension and other cardiovascular risk factors in Brazzaville 2004.

23. Pearl C, Constant R, Eric B et al. (2009) Survey of risk factors of noncommunicable diseases in Libreville and Owendo 2009.

24. Kayima J, Wanyenze RK, Katamba A, Leontsini E, Nuwaha F (2013) Hypertension aware-ness, treatment and control in Africa: a systematic review. BMC Cardio-vascular Disorders 13: 54.

25. World Health Organization (2006) Control of hypertension on medication: a comparative analysis of national surveys in 20 countries.

26. International Diabetes Federation (2003) Diabetes atlas. 2nd edition Bruxelles: IDF; 2003.

27. International Diabetes Federation (2010) Diabetes atlas. 4th edition Bruxelles:IDF; 2010

28. Fakhfakh R, Hsairi M, Maalej M, Achour N et Nacef T (2002) Smoking in Tunisia: Behaviors and knowledge. Bulletin of World Health Organization 80: 350-356.

Copyright: (c) 2016 Mbaye A, et al. This is an open-access article distributed under the terms of the Creative Commons Attribution License, which permits unrestricted use, distribution, and reproduction in any medium, provided the original author and source are credited. 